OPEN ACCESS

Edited by:

Silvia Demoulin-Alexikova, Université de Lorraine, France

Reviewed by:

Noriyuki Ohkura,

Kanazawa University, Japan

Cyril Etienne Schweitzer,

Université de Lorraine, France

*Correspondence:

Nilita Sood

ons10@queensu.ca

Specialty section:

This article was submitted to

Respiratory Physiology,

a section of the journal

Frontiers in Physiology

Received: 22 April 2020 Accepted: 11 September 2020

Published: 06 October 2020

Citation:

Sood N, Wasilewski NV, Day AG,

Wall T, Fisher T, Fisher JT and

Lougheed MD (2020)

Methacholine-Induced Cough in the Absence of Asthma: Insights

From Impulse Oscillometry.

Front. Physiol. 11:554679

doi: 10.3389/fphys.2020.554679

\section{Methacholine-Induced Cough in the Absence of Asthma: Insights From Impulse Oscillometry}

\author{
Nilita Sood ${ }^{1,2 *}$, Nastasia V. Wasilewski ${ }^{1,2}$, Andrew G. Day ${ }^{3}$, Taylar Wall' ${ }^{1}$, Thomas Fisher ${ }^{1}$, \\ John T. Fisher ${ }^{2}$ and M. Diane Lougheed ${ }^{1,2,3}$ \\ 'Department of Medicine, School of Medicine, Faculty of Health Sciences, Queen's University, Kingston, ON, Canada, \\ ${ }^{2}$ Department of Biomedical and Molecular Sciences, School of Medicine, Faculty of Health Sciences, Queen's University, \\ Kingston, ON, Canada, ${ }^{3}$ Kingston General Health Research Institute, Kingston Health Sciences Centre, Queen's University, \\ Kingston, ON, Canada
}

Introduction: The pathophysiologic differences between methacholine-induced cough but normal airway sensitivity (COUGH) and healthy individuals (CONTROL) are incompletely understood and may be due to differences in the bronchodilating effect of deep inspirations (DIs). The purpose of this study is to compare the bronchodilating effect of Dls in individuals with classic asthma (CA), cough variant asthma (CVA), and COUGH with CONTROL and to assess impulse oscillometry (IOS) measures as predictors of the bronchodilating effect of Dls.

Methods: A total of 43 adults [18 female; $44.8 \pm 12.3$ years (mean \pm SD); $n=11$ $\mathrm{CA}, n=10 \mathrm{CVA}, n=7 \mathrm{COUGH}, n=15 \mathrm{CONTROL}]$ underwent modified highdose methacholine challenge, with IOS and partial/maximal expiratory flow volume (PEFV/MEFV) maneuvers (used to calculate DI Index) to a maximum change $(\Delta)$ in $\mathrm{FEV}_{1}$ of $50 \%$ from baseline (MAX). Cough count and dyspnea were measured at each dose. The relation between IOS parameters and DI Index was assessed at baseline and MAX using multivariable linear regression analysis.

Results: Cough frequency, dyspnea intensity, and baseline peripheral resistance (R5R20) were significantly greater in COUGH compared with CONTROL $p=0.006$, $p=0.029$, and $p=0.035$, respectively). At MAX, the DI Index was significantly lower in COUGH $(0.01 \pm 0.36)$ compared with CA $(0.67 \pm 0.97, p=0.008)$, CVA $(0.51 \pm 0.73, p=0.012)$, and CONTROL $(0.68 \pm 0.45, p=0.005)$. Fres and R5-R20 were independent IOS predictors of the DI Index.

Conclusion: The bronchodilating effect is impaired in COUGH and preserved in mild CA, CVA, and CONTROL. Increased peripheral airway resistance and decreased resonant frequency are associated with a decreased DI Index. COUGH is a clinical phenotype distinct from healthy normals and asthma.

Keywords: asthma, cough, cough variant asthma, chronic cough, deep inspiration, impulse oscillometry, methacholine, methacholine challenge test 


\section{INTRODUCTION}

Asthma is a chronic inflammatory disorder of the airways associated with a variable degree of airway hyperresponsiveness and airflow obstruction, producing symptoms of chest tightness, wheeze, cough, and dyspnea. When cough presents as the sole or predominant symptom of asthma, it is described as cough variant asthma (CVA) (Glauser, 1972; Corrao et al., 1979). CVA is typically diagnosed when individuals with chronic cough have evidence of asthma on pulmonary function tests (reversible airflow obstruction or airway hyperresponsiveness to non-specific stimuli), and report resolution of their cough with standard asthma therapy (Irwin et al., 2006). However, the underlying pathophysiologic mechanisms differentiating classic asthma (CA) and CVA are not fully understood.

Recent studies have identified a group of individuals with chronic cough (and suspected CVA) who cough during highdose methacholine challenge but have normal airway sensitivity (COUGH) (Wasilewski et al., 2015, 2018; Sood et al., 2018). During methacholine challenge testing, these individuals cough more frequently and develop significant dynamic hyperinflation, compared to individuals with CA (Wasilewski et al., 2015), and develop significant increases in esophageal pressures before a cough, which partially resolves following a deep inspiration (DI) and cough (Sood et al., 2018). This partial normalization is likely due to a combination of the bronchoprotective and bronchodilating effects of a DI (Ohkura et al., 2009), where an inhalation to total lung capacity (TLC) dilates the airways to minimize airflow limitation and subsequently protects against bronchoconstriction.

Since both maximal inspiratory and maximal forced expiratory maneuvers involve DIs, plethysmography and spirometry measurements reflect the combination of the airway smooth muscle response to the inhaled methacholine and the response to a DI. Impulse oscillometry (IOS), a variant of the forced oscillation technique, uses rectangular pressure waves superimposed on an individual's tidal breathing to assess the degree of obstruction in the central and peripheral airways (LaPrad and Lutchen, 2008). Several studies have shown IOS to be more sensitive than spirometry for detecting peripheral airway abnormalities and assessing bronchodilator responses in asthma (Marotta et al., 2003; Kaminsky, 2011). Because IOS does not require DIs to generate data about the mechanical properties of the respiratory system, it assesses peripheral airway function in the absence of DIs (Navajas and Farré, 2001; Chapman et al., 2009) making it particularly valuable as a tool to tease out the significance of the bronchoprotective and bronchodilating effects of a DI.

Wasilewski et al. (2015) reported that the bronchodilating effect of DIs is preserved in individuals with CVA and CA. However, in the absence of comparison with healthy individuals, the clinical significance of the responses in the COUGH group remained uncertain. In order to tease out the clinical relevance of COUGH, we compared the physiologic responses and the bronchodilating effect of a DI in response to highdose methacholine in CA, CVA, and COUGH to healthy individuals (without asthma, chronic cough, or asymptomatic airway hyperresponsiveness, CONTROL). We chose highdose methacholine provocation to induce physiologic changes, especially for the COUGH and CONTROL groups where responses are often mild, even at the methacholine doses as high as $256 \mathrm{mg} / \mathrm{mL}$. We hypothesized that the bronchodilating effect of a DI would be absent or impaired in individuals with CA, impaired in individuals with CVA and COUGH, and preserved in CONTROL. Another objective of this study was to investigate IOS measures of pulmonary resistance and reactance as potential determinants of DI-induced bronchodilation in our study population. Some preliminary results have been previously reported in the form of an abstract (Sood et al., 2017).

\section{MATERIALS AND METHODS}

\section{Participants}

Participants with CA, CVA, and COUGH were recruited from patients (age 18-65 years) referred to a tertiary care cough clinic in Kingston, as previously described (Wasilewski et al., 2015, 2018). They were invited to participate if they had chronic cough because of suspected or proven CA or CVA. Healthy participants, aged 18-65 years, with no history of asthma, allergies (seasonal or otherwise), rhinitis/sinusitis, eczema, and/or chronic cough were recruited using print advertisements in Kingston, as previously described (Sood et al., 2018).

The study was approved by the Queen's University Health Sciences Research Ethics Board and received a Letter of No Objection from Health Canada Therapeutic Products Directorate. The clinical trial was registered on www.clinicaltrials.gov (NCT01659476).

\section{Study Design}

Participants had previously participated in other studies involving high-dose methacholine testing and had already been classified as CA, CVA, COUGH (Wasilewski et al., 2015, 2018), and CONTROL (Sood et al., 2018). The following definitions were used:

(a) CA: Episodic respiratory symptoms occurring in association with variable airflow obstruction and/or methacholine $\mathrm{PC}_{20} \leq 16 \mathrm{mg} / \mathrm{mL}$ (Canadian Thoracic Society Asthma Guidelines; Lougheed et al., 2012);

(b) CVA: Asthma $\left(\mathrm{PC}_{20} \leq 16 \mathrm{mg} / \mathrm{mL}\right)$ with chronic cough as the sole or predominant symptom, and history of response to asthma treatment (such as inhaled corticosteroids or 1 week trial of bronchodilator therapy; Irwin et al., 2006);

(c) COUGH: Chronic cough (Irwin et al., 2006) as the sole or predominant symptom and a negative methacholine challenge $\left(\mathrm{PC}_{20}>16 \mathrm{mg} / \mathrm{mL}\right)$ with the presence of cough (Turcotte and Lougheed, 2011; Wasilewski et al., 2015); and

(d) CONTROL: No history of asthma, allergies (seasonal or otherwise), rhinitis/sinusitis, eczema and/or chronic cough, FeNO < $25 \mathrm{ppb}$, and a negative MCh challenge $\left(\mathrm{PC}_{20}>16 \mathrm{mg} / \mathrm{mL}\right)$ (Sood et al., 2018).

After written informed consent, a detailed medical history was taken. All participants were screened for exclusion criteria, as 
previously described (Wasilewski et al., 2015, 2018; Sood et al., 2018). CONTROL participants completed the self-administered comorbidity questionnaire (Sangha et al., 2003) to assess any existing comorbidities. They had their exhaled fraction of nitric oxide ( $\mathrm{FeNO}$ ) measured to exclude baseline airway inflammation. Participants with no asthma or cough but with FeNO $>25 \mathrm{ppb}$ were also excluded from the CONTROL group. Participants with CA, CVA, and COUGH completed the Mini Asthma Quality of Life Questionnaire (Juniper et al., 1999) and the Leicester Cough Questionnaire (Birring et al., 2003). Data for these questionnaires have been previously published (Wasilewski et al., 2015).

Participants then completed baseline pulmonary function testing, including IOS measurements, spirometry, body plethysmography, maximal and partial expiratory flow volume curves (MEFV and PEFV, respectively), followed by a modified high-dose methacholine challenge protocol (Figure 1). Shortacting bronchodilators were withheld for $8 \mathrm{~h}$, long-acting bronchodilators beta-agonists were held $48 \mathrm{~h}$, tiotropium bromide was withheld for $72 \mathrm{~h}$, and leukotriene receptor antagonists for $96 \mathrm{~h}$ prior to testing as per the American Thoracic Society guidelines (Crapo et al., 2000). We did not collect information about use of antihistamines usage in the participants.

\section{Measurements}

\section{Exhaled Nitric Oxide Measurement}

Only CONTROL participants had FeNO measured according to American Thoracic Society standards (Dweik et al., 2011), using NIOX MINO ${ }^{\circledR}$ (Aerocrine $\mathrm{AB}$, Solna, Sweden). FeNO measurements were performed prior to the high-dose methacholine test. After inhaling room air, participants exhaled from TLC (without nose clips) into the NIOX MINO ${ }^{\circledR}$ device.

\section{Pulmonary Function Testing}

Spirometry, body plethysmography, and specific airway resistance were performed using 6200 Autobox DL (SensorMedics, Yorba Linda, CA, United States) according to the recommended techniques (Miller et al., 2005). Participants were trained in performing the lung volume maneuvers by a Registered Respiratory Therapist during the baseline testing. Lung volumes and specific airway resistance (sRaw) were determined by constant-volume body plethysmography. Panting frequency was standardized at $1 \mathrm{~Hz}$ to minimize the potential for frequency-dependent overestimation of thoracic gas volume during bronchoconstriction (Rodenstein and Stânescu, 1983). Inspiratory capacity (IC) was measured using body plethysmography. TLC was calculated as the sum of functional residual capacity (FRC) and IC. Dynamic hyperinflation was assessed using change in residual volume (RV) and RV/TLC.

The predicted values used for spirometry, lung volumes, and airway resistance were by Briscoe and Dubois (1958), Goldman and Becklake (1959), and Morris et al. (1971), respectively.

\section{Methacholine Challenge}

High-dose methacholine challenge testing was performed using Provocholine ${ }^{\circledast}$ (methacholine chloride; Methapharm Ltd., Brantford, ON, Canada) according to a standardized high-dose tidal breathing protocol (Sterk et al., 1985). Isotonic saline (0.9\%) was first administered as a control, followed by participants inhaling methacholine doses for 2 min while seated upright. The methacholine doses were administered within approximately 5 min intervals of each other (Crapo et al., 2000). Immediately following each methacholine dose, IOS measurements were obtained. Subsequently, PEFV and MEFV maneuvers were performed according to a published method (Sterk et al., 1985) to assess the bronchodilating effect of DIs (Supplementary Figure S1). Plethysmographic measurements were obtained at baseline, after inhalation of nebulized normal saline (0.9\%), and at the maximum response to methacholine (MAX). MAX was defined as any of the following: (i) a decline $\mathrm{FEV}_{1}$ to $50 \%$ of the baseline value; (ii) the mean value of $\mathrm{FEV}_{1}$ on a response "plateau" (defined as a change in $\mathrm{FEV}_{1}$ of $<5 \%$ over two or more dose steps after a fall of $>10 \%$ from the baseline value); (iii) the change in $\mathrm{FEV}_{1}$ after the highest methacholine dose $(256 \mathrm{mg} / \mathrm{mL})$ had been delivered; or (iv) the change in $\mathrm{FEV}_{1}$ at the cessation of testing at the participant's request.

After testing, bronchoconstriction, if present, was reversed with inhaled salbutamol (200 $\mu$ g every $10 \mathrm{~min}$ by metered dose inhaler and spacer), until the $\mathrm{FEV}_{1}$ was within $10 \%$ of the baseline value. The provocative concentration of methacholine causing a $20 \%$ fall in $\mathrm{FEV}_{1}$ from baseline $\left(\mathrm{PC}_{20}\right)$ was interpolated from $\log _{10}$ dose-response curves.

\section{Symptom Evaluation}

Cough was defined as an audible expiratory maneuver against a closed glottis (Morice, 2008; Chung et al., 2009). Coughs during the high-dose methacholine test were manually counted and recorded using a microphone. Dyspnea was defined as previously described (Lougheed et al., 1993). Participants were asked to rate their difficulty breathing in, breathing out, and their overall difficulty breathing using the modified Borg scale (Borg, 1982).

Cough frequency and dyspnea were assessed at baseline, after isotonic saline, and at each methacholine dose step. Any coughs occurring in response to methacholine (not including any coughs at baseline, after isotonic saline, and after salbutamol inhalation) were summed for analysis.

\section{Impulse Oscillometry}

Impulse oscillometry measurements were performed prior to spirometry, immediately after the isotonic saline/methacholine dose (Supplementary Figure S1). Measurements were obtained using the Jaeger Masterscreen IOS system (Erich Jaeger, Hoechberg, Germany), as previously described (Oostveen et al., 2003; Borrill et al., 2005). During each acquisition, participants were instructed to breathe through a mouthpiece in a relaxed manner while seated upright, wearing a nose clip, and supporting their cheeks using both hands. Participants were trained by a Registered Respiratory Therapist not to occlude the mouthpiece with their tongue and monitored during data acquisition. Each participant took about $60 \mathrm{~s}$ for the IOS measurement. Due to time constraints, IOS measurements were performed twice at each dose step. Coherence values used were $>0.6$ at $5 \mathrm{~Hz}$ and $\geq 0.8$ at $10 \mathrm{~Hz}$ or more (Brashier and Salvi, 2015). After each measurement, tidal volume, respiratory system 


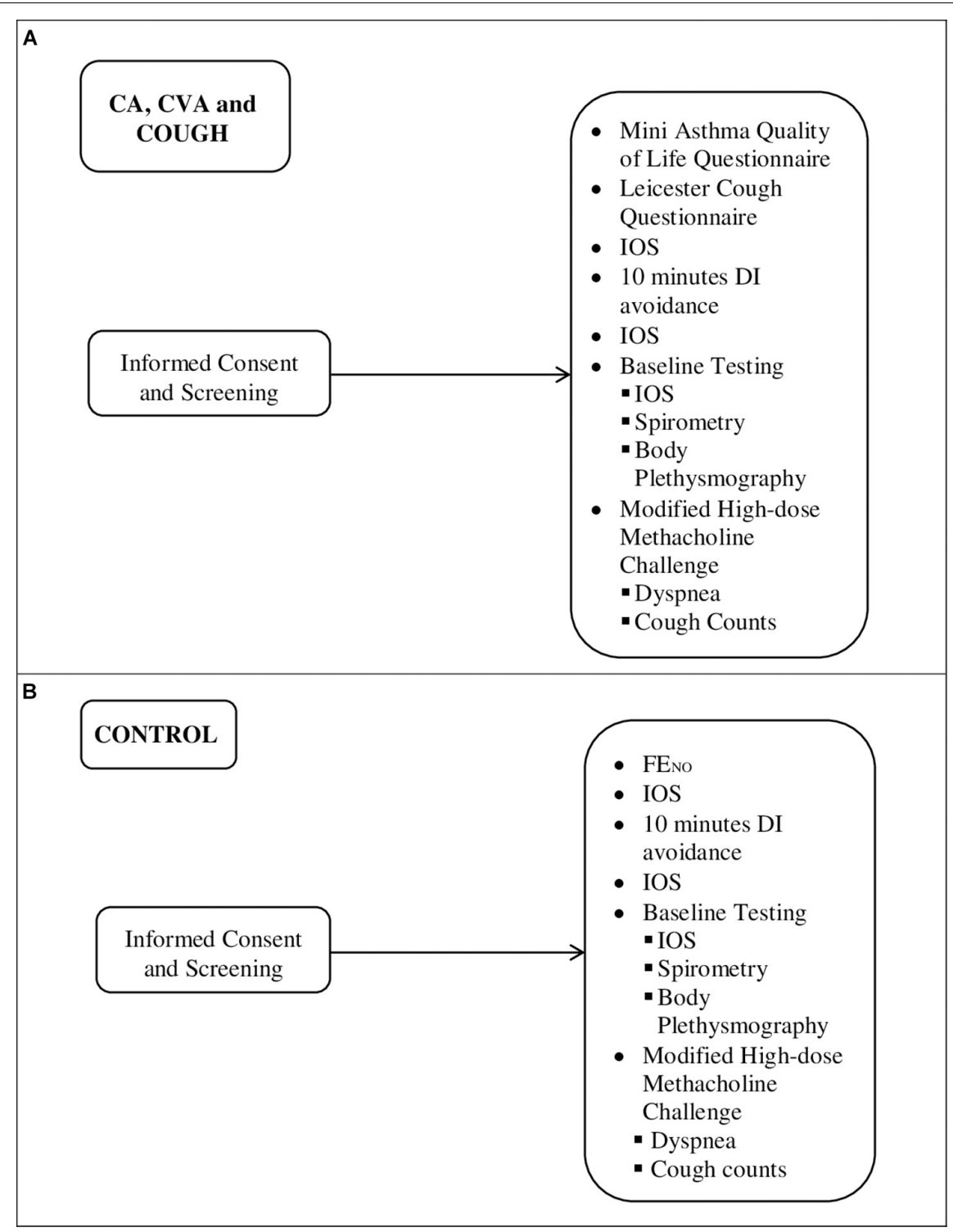

FIGURE 1 | Outline of sequence of testing for (A) CA $(n=11)$, CVA $(n=10)$, and COUGH $(n=7)$ and (B) CONTROL $(n=15)$. FE $E_{N O}$, exhaled fraction of nitric oxide.

resistance (Rrs), and reactance (Xrs) were displayed on the computer screen. All data were visually inspected and checked for artifacts, such as irregular breathing, hyperventilation, leakages, or swallowing. Measurements with artifacts were discarded and, if possible, repeated.

\section{Bronchodilating Effect}

The bronchodilating effect of DIs was examined by comparing the flow difference between the PEFV and MEFV at an isovolume of $40 \%$ of the control vital capacity $\left(\mathrm{PEF}_{40}\right.$ and $\mathrm{MEF}_{40}$, respectively) (Ohkura et al., 2010). Specifically, these were used to calculate DI index (Fujimura et al., 1990; Ohkura et al., 2010), as follows:

$$
\left(M E F_{40}-P E F_{40}\right) / P E F_{40}
$$

\section{Statistical Analysis}

All data are expressed as mean \pm SD unless indicated otherwise. The analyses of responses to high-dose methacholine challenge were performed using SPSS version 22.0.0 (IBM Corporation, Chicago, IL, United States). Previously published data (Wasilewski et al., 2015) were used to compare the responses to high-dose methacholine for CONTROL participants $(n=15)$ to individuals CA $(n=11)$, CVA $(n=10)$, and COUGH $(n=7)$. For this comparison, the raw values for IOS parameters were used to assess between-group differences. Between-group comparisons were made using ANOVA with Bonferroni correction for multiple comparisons or KruskalWallis tests with post hoc Mann-Whitney $U$ tests. Within-group comparisons were made using paired $t$-tests or Wilcoxon signedrank tests (paired). 


\section{Assessing IOS Measures as Predictors of DI Index}

The goal of this correlation and regression analysis was to assess if IOS measures of pulmonary resistance and reactance predict DI index independently of age, sex, height, BMI, spirometry, and lung volume. The correlation and linear regression analyses were performed using SAS version 9.4 (SAS Institute Inc., Cary, NC, United States). Only measures at baseline and at MAX were used. Detailed description of the analysis is presented in the Supplementary Material.

\section{RESULTS}

Tables 1, 2 contain the baseline characteristics for the CA, CVA, COUGH, and CONTROL groups.

\section{Baseline Pulmonary Function}

At baseline, the \%predicted $\mathrm{FEV}_{1}$ for $\mathrm{COUGH}$ was comparable to both CA and CVA, and significantly lower than CONTROL. There were no other significant differences in the baseline spirometry and lung volume measures within groups. Baseline FeNO for CONTROL participants was $<25 \mathrm{ppb}(16.3 \pm 5.3 \mathrm{ppb})$.

At baseline, R5-R20 was comparable between the CA, CVA, and COUGH groups, and significantly elevated compared to CONTROL (Supplementary Table S1). All other baseline IOS measures were comparable between COUGH and CONTROL, and COUGH and CVA. However, COUGH had significantly lower AX and Fres compared to CA (Table 1 and Supplementary Table S1). Participants with CA and CVA also had elevated AX and Fres compared to CONTROL at baseline.

\section{Responses to High-Dose Methacholine}

Group responses to high-dose methacholine are presented in Tables 2-4. Cough frequency in COUGH (32.0 \pm 27.1$)$ was comparable to CVA $(33.0 \pm 27.1 ; p=0.775)$ and significantly higher than both CA $(1.7 \pm 2.9 ; p=0.004$ and 0.001 for COUGH and CVA, respectively) and CONTROL (5.6 \pm 3.7; $p=0.006$ and 0.001 for COUGH and CVA, respectively). Similarly, overall dyspnea intensity in COUGH $(2.8 \pm 1.8)$ was significantly higher than CONTROL $(0.5 \pm 0.9$; $p=0.029)$, and comparable to that experienced by CA $(2.7 \pm 1.7 ; p=0.631)$ and CVA $(2.1 \pm 1.2 ; p=0.728)$. For participants with CA, CVA, and COUGH, dyspnea intensity on the Modified Borg Scale corresponded to "Moderate" at MAX.

The percent change in $\mathrm{FEV}_{1}\left(\% \Delta \mathrm{FEV}_{1}\right)$ was comparable in COUGH and CONTROL, but significantly lower compared to CA. However, the $\triangle \mathrm{FEV}_{1}$ (L) was significantly greater in COUGH $(-0.70 \pm 0.50 \mathrm{~L})$ compared to CONTROL $(-0.58 \pm 0.41 \mathrm{~L}, p=0.042)$. All groups had significant changes in the mid-to-late flows (\% predicted, \%pr) from baseline, but these were comparable between groups (Table 2). Compared to baseline, participants with CA, CVA, and COUGH developed significant dynamic hyperinflation [IC (\%pr)], but only CA and CVA developed significant gas trapping $[\mathrm{RV}(\% \mathrm{pr})$ and $\mathrm{RV} / \mathrm{TLC}(\% \mathrm{pr})]$. IC (\%pr) decreased more in CA and CVA, compared with COUGH and CONTROL, although the difference between groups was only of borderline statistical significance $(p=0.054)$. Gas trapping was comparable in COUGH, CVA, and CONTROL, but significantly greater in CA.

Most IOS parameters increased significantly from baseline to MAX in our four groups. Like CONTROL, the change in total resistance (R5) in COUGH could be attributed to a significant change in central resistance (R20). At MAX, COUGH had comparable R5-R20 to CONTROL, which was significantly lower than that in CA. COUGH also had comparable Fres, X5, and AX measures at MAX compared with CONTROL, but significantly different from CA and CVA. $\triangle \mathrm{X} 5$ and $\triangle \mathrm{AX}$ were also similar in CONTROL and COUGH groups.

\section{Bronchodilating Index}

Figure 2 shows representative PEFV/MEFV curves for CA, CVA, COUGH, and CONTROL at baseline and MAX, respectively, used to calculate the DI index. The DI index was comparable for all four groups at baseline (Table 1). The change in the DI index from baseline to MAX was significant in all four groups $(p=0.04$, $p=0.01, p=0.008$, and $p<0.001$ for CA, CVA, COUGH, and CONTROL, respectively).

At MAX, although positive, the DI index for COUGH group $(0.01 \pm 0.36)$ was significantly lower compared to the CA $(0.67 \pm 0.97)$, CVA $(0.51 \pm 0.73)$, and CONTROL $(0.67 \pm 0.44)$ groups, indicating that the bronchodilating effect in COUGH was impaired (Figure 3).

\section{Assessing IOS Measures as Predictors of DI Index}

When assessing the IOS measures [ $\log (\mathrm{R} 5), \log (\mathrm{R} 20), \log (\mathrm{R} 5-$ $\mathrm{R} 20),-\log (-\mathrm{X} 5), \log (\mathrm{AX}), \log ($ Fres $)]$ as predictors of DI-index, we attempted to adjust for age, sex, height, BMI, spirometry measures, and lung volume measures. The correlations for the variables are summarized in Supplementary Table S1. The first five principal components (PCs) of these 22 variables had eigenvalues $\geq 1.0$ and collectively explained $85 \%$ of the variance in these 22 variables and $32 \%$ of the variance in the DI-index (Supplementary Table S2). For comparison, age, sex, height, and weight collectively explained $18 \%$ of the variance in the DIindex.

Table 5 provides the Pearson correlations between IOS measures and the DI index. After controlling for the five PCs described above, the partial correlations ranged from 0.28 for $\log (\mathrm{R} 20)$ up to 0.59 for $\log$ (Fres) (Table 5). All the partial correlations except R20 had a false discover rate $<5 \%$. Although the estimated magnitudes of the unadjusted Pearson correlations were clinically meaningful, they were consistently smaller than the partial correlations and generally not statistically significant.

Without adjustment for other covariates, the six IOS variables explained $33 \%$ (adjusted $R^{2}=21 \%$ ) of the variance in the DI index $(p=0.027)$ (see Supplementary Table S3 for details of the multiple regression models). After controlling for the five PCs, the selection method described in the 
TABLE 1 | Participant characteristics and baseline lung function measures.

\begin{tabular}{|c|c|c|c|c|c|}
\hline & $\begin{array}{c}\text { CA } \\
(n=11)\end{array}$ & $\begin{array}{c}\text { CVA } \\
(n=10)\end{array}$ & $\begin{array}{l}\text { Cough } \\
(n=7)\end{array}$ & $\begin{array}{l}\text { Control } \\
(n=15)\end{array}$ & $P$-value \\
\hline Age (years) & $39.8 \pm 11.9^{\lessgtr}$ & $53.0 \pm 9.9$ & $40.9 \pm 11.7^{\S}$ & $31.4 \pm 7.2^{\S}$ & 0.004 \\
\hline $\mathrm{BMI}\left(\mathrm{kg} / \mathrm{m}^{2}\right)$ & $32.8 \pm 6.3$ & $28.2 \pm 7.0$ & $26.7 \pm 7.5$ & $26.2 \pm 7.4$ & 0.120 \\
\hline Smoking history (pack year) & $5.0 \pm 3.5^{(n=2)}$ & $1.2^{(n=1)}$ & $5.7 \pm 6.1^{(n=2)}$ & $5.0^{(n=1)}$ & N/A \\
\hline Plateau (\%) & 45.5 & 40.0 & 71.4 & 40.0 & 0.556 \\
\hline Eczema (\%) & 9.0 & 20.0 & 14.3 & 0.0 & 0.387 \\
\hline Rhinitus/sinusitis (\%) & 45.5 & 36.4 & 57.1 & $0.0^{\#}$ & 0.016 \\
\hline $\mathrm{PC}_{20} \mathrm{MCh}(\mathrm{mg} / \mathrm{mL})$ & $2.19 \pm 2.32$ & $5.59 \pm 4.09$ & $49.3 \pm 17.0^{(n=4) \#}$ & $93.4 \pm 85.4^{(n=4) \#}$ & $<0.001$ \\
\hline MAX MCh (mg/mL) & $7.36 \pm 5.97$ & $50.0 \pm 45.7$ & $137.1 \pm 86.1^{\psi \S}$ & $256.0^{\psi \$}$ & $<0.001$ \\
\hline \multicolumn{6}{|l|}{ Medication usage } \\
\hline SABA use (\%) & 90.1 & 70.0 & 71.4 & $0.0 \psi \S \#$ & $<0.001$ \\
\hline \multicolumn{6}{|l|}{ Sensory responses } \\
\hline Borg overall & $0.1 \pm 0.2^{(n=10)}$ & $0.5 \pm 0.7^{(n=8)}$ & $0.8 \pm 1.1^{(n=6)}$ & 0.0 & 0.034 \\
\hline \multicolumn{6}{|l|}{ Spirometry } \\
\hline $\mathrm{FEV}_{1}(\% \mathrm{pr})$ & $88.2 \pm 19.1$ & $82.7 \pm 12.2$ & $99.4 \pm 19.8$ & $106.9 \pm 10.9 \psi \S$ & 0.002 \\
\hline FVC (\%pr) & $99.9 \pm 19.8$ & $95.8 \pm 15.4$ & $104.7 \pm 20.4$ & $103.4 \pm 22.7$ & 0.768 \\
\hline $\mathrm{FEV}_{1} / \mathrm{FVC}(\% \mathrm{pr})$ & $89.9 \pm 6.2$ & $92.2 \pm 9.0$ & $96.4 \pm 9.5$ & $98.4 \pm 8.2$ & 0.233 \\
\hline $\mathrm{FEF}_{25-75 \%}(\% \mathrm{pr})$ & $70.0 \pm 23.1$ & $74.7 \pm 19.9$ & $90.4 \pm 36.9$ & $93.6 \pm 23.5$ & 0.081 \\
\hline \multicolumn{6}{|l|}{ Lung volumes } \\
\hline TLC (\%pr) & $102.6 \pm 19.4$ & $100.8 \pm 17.1$ & $105.7 \pm 7.26$ & $103.1 \pm 13.8$ & 0.935 \\
\hline RV (\%pr) & $107.3 \pm 45.8$ & $109.8 \pm 24.8$ & $116.1 \pm 22.4$ & $92.9 \pm 42.1$ & 0.504 \\
\hline IC (\%pr) & $125.4 \pm 36.5$ & $115.9 \pm 22.9$ & $104.5 \pm 12.3$ & $108.0 \pm 16.2$ & 0.227 \\
\hline \multicolumn{6}{|l|}{ Impulse oscillometry } \\
\hline \multicolumn{6}{|l|}{ LCQ scores } \\
\hline Physical domain & $6.5 \pm 0.5$ & $5.1 \pm 1.0^{\psi}$ & $5.3 \pm 1.1$ & - & $0.031^{*}$ \\
\hline Psychological domain & $6.8 \pm 0.1$ & $4.6 \pm 1.4^{\psi}$ & $5.4 \pm 1.1$ & - & $0.004^{\star}$ \\
\hline Social domain & $6.7 \pm 0.2$ & $4.6 \pm 1.2^{\psi}$ & $4.9 \pm 1.3^{\psi}$ & - & $0.002^{\star}$ \\
\hline Total score & $19.9 \pm 0.9$ & $14.4 \pm 3.4^{\psi}$ & $15.6 \pm 3.4^{\psi}$ & - & $0.002^{\star}$ \\
\hline \multicolumn{6}{|l|}{ Mini-AQLQ scores } \\
\hline Symptoms & $5.9 \pm 0.8$ & $5.1 \pm 1.0$ & $5.7 \pm 1.4$ & - & $0.305^{*}$ \\
\hline Activity limitation & $6.6 \pm 0.4$ & $6.2 \pm 1.1$ & $5.8 \pm 1.5$ & - & $0.347^{\star}$ \\
\hline Emotional limitation & $6.3 \pm 0.8$ & $5.9 \pm 1.2$ & $5.5 \pm 0.9$ & - & $0.422^{\star}$ \\
\hline Environmental limitation & $6.2 \pm 0.7$ & $5.0 \pm 1.2$ & $4.8 \pm 1.4$ & - & $0.059^{*}$ \\
\hline Overall score & $6.2 \pm 0.5$ & $5.5 \pm 1.2$ & $5.5 \pm 1.0$ & - & $0.181^{*}$ \\
\hline
\end{tabular}

All values are mean $\pm S D$, except \# denoting median \pm median absolute deviation and \% denoting the proportion of participants. Bolded values indicate significant differences. BMI, body mass index; CA, classic asthma; COUGH, methacholine-induced cough but normal airway sensitivity; CVA, cough variant asthma; CONTROL, healthy participants; MCh, methacholine; $P C_{20}$, provocative concentration eliciting a $20 \%$ decline in FEV from baseline; MAX MCh, methacholine dose eliciting maximum decline in FEV 1 from baseline; ICS, inhaled corticosteroid; LABA, long-acting B2-agonist; SABA, short-acting B2-agonist; FEV 1 , forced expiratory volume in $1 \mathrm{~s}$; FVC, forced vital capacity; FEV $1 / F V C$, forced expiratory volume in $1 \mathrm{~s}$ divided by forced vital capacity; FEF $25-75 \%$, mean forced expiratory flow during the middle half of the forced vital capacity; IC, inspiratory capacity; LCQ, Leicester Cough Questionnaire; Mini-AQLQ, Mini-Asthma Quality of Life Questionnaire; RV, residual volume; TLC, total lung capacity; $R 5$, resistance at $5 \mathrm{~Hz}$ (total respiratory resistance); $R 5-R 20$, frequency dependence of Rrs (R5 minus R20, peripheral respiratory resistance); $R 20$, resistance at $20 \mathrm{~Hz}$ (central respiratory resistance); $X 5$, reactance at $5 \mathrm{~Hz}$ (peripheral reactance); $A X=$ area under the reactance curve below resonant frequency; Fres, resonant frequency; DI, deep inspiration. ${ }^{*} p<0.05$ compared with CA. ${ }^{s} p<0.05$ compared with CVA. ${ }^{*} p$-values were calculated using ANOVA with post hoc Bonferroni comparisons for CA, CVA, and COUGH only. 
TABLE 2 | Log-transformed impulse oscillometry measures.

\begin{tabular}{|c|c|c|c|c|c|}
\hline & $\begin{array}{c}\text { CA } \\
(n=11)\end{array}$ & $\begin{array}{c}\text { CVA } \\
(n=10)\end{array}$ & $\begin{array}{l}\text { Cough } \\
(n=7)\end{array}$ & $\begin{array}{l}\text { Control } \\
(n=15)\end{array}$ & $P$-value \\
\hline \multicolumn{6}{|l|}{ Baseline } \\
\hline $\log (\mathrm{R} 5)$ & $1.65 \pm 0.31$ & $1.43 \pm 0.31$ & $1.32 \pm 0.44$ & $1.26 \pm 0.27 \psi$ & 0.027 \\
\hline Log (R20) & $1.38 \pm 0.33$ & $1.21 \pm 0.31$ & $1.14 \pm 0.39$ & $1.24 \pm 0.26$ & 0.427 \\
\hline $\log (R 5-R 20)$ & $0.16 \pm 0.45$ & $-0.23 \pm 0.41$ & $-0.55 \pm 0.71$ & $-1.53 \pm 0.72^{\psi \S \#}$ & $<0.001$ \\
\hline$-\log (-X 5)$ & $-0.54 \pm 0.49$ & $-0.27 \pm 0.20$ & $-0.09 \pm 0.64$ & $0.42 \pm 0.57^{\psi \S}$ & $<0.001$ \\
\hline $\log (A X)$ & $2.12 \pm 0.76$ & $1.58 \pm 0.43$ & $0.91 \pm 1.16^{\psi}$ & $-0.07 \pm 1.01^{\psi \S}$ & $<0.001$ \\
\hline Log (Fres) & $2.82 \pm 0.20$ & $2.64 \pm 0.13$ & $2.33 \pm 0.46^{\psi}$ & $2.13 \pm 0.23^{\psi \S}$ & $<0.001$ \\
\hline \multicolumn{6}{|l|}{$\operatorname{Max}$} \\
\hline $\log (\mathrm{R} 5)$ & $2.06 \pm 0.28^{\ddagger \ddagger}$ & $1.85 \pm 0.33^{\ddagger \ddagger}$ & $1.77 \pm 0.49^{\ddagger \ddagger}$ & $1.79 \pm 0.26^{\ddagger \ddagger}$ & 0.172 \\
\hline $\log (\mathrm{R} 20)$ & $1.34 \pm 0.24$ & $1.22 \pm 0.20$ & $1.36 \pm 0.34$ & $1.49 \pm 0.25^{\ddagger \ddagger}$ & 0.099 \\
\hline Log (R5-R20) & $1.36 \pm 0.41^{\text {护 }}$ & $1.04 \pm 0.52^{\ddagger \ddagger}$ & $0.38 \pm 1.03^{\psi}$ & $0.34 \pm 0.78^{\psi}$ & 0.001 \\
\hline$-\log (-X 5)$ & $-1.68 \pm 0.60^{\ddagger \ddagger}$ & $-1.45 \pm 0.52^{\ddagger \ddagger}$ & $-0.62 \pm 0.93^{(n=6) \neq \ddagger \psi \S}$ & $-0.62 \pm 0.43^{\ddagger \neq \psi \S}$ & $<0.001$ \\
\hline $\log (A X)$ & $3.73 \pm 0.73^{\text {㧊 }}$ & 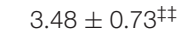 & $2.24 \pm 1.38^{\ddagger \neq \psi \S}$ & $2.34 \pm 0.83^{\ddagger \neq \psi \S}$ & $<0.001$ \\
\hline Log (Fres) & $3.30 \pm 0.28^{\ddagger \ddagger}$ & $3.22 \pm 0.20^{\ddagger \ddagger}$ & $2.84 \pm 0.43^{\ddagger \neq} \psi$ & $2.92 \pm 0.31^{\ddagger \neq \psi}$ & 0.003 \\
\hline
\end{tabular}

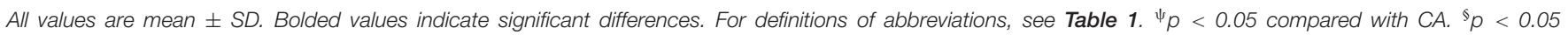
compared with CVA. ${ }^{\#} p<0.05$ compared with COUGH. ${ }^{\ddagger \ddagger} p<0.05$ compared with baseline using paired t-test.

Supplementary Methods retained $\log (\mathrm{R} 5-\mathrm{R} 20)$ and $\log ($ Fres $)$ from the six IOS variables.

The stability of the model selection across 10,000 bootstrap samples is described in Supplementary Table S4. After controlling for the five PCs, $\log$ (Fres) was selected in $90 \%$ of the models and $\log (\mathrm{R} 5-\mathrm{R} 20)$ in $47 \%$.

\section{DISCUSSION}

Our main finding was that the DI index for COUGH was significantly lower compared to CA, CVA, and CONTROL, suggesting that the bronchodilating effect of DIs is impaired in individuals with COUGH, but preserved in CA, CVA, and health. We have recently shown that individuals with COUGH develop significant small airway obstruction, but experience only a partial normalization of end-expiratory esophageal pressures and mid-to-late flows after a cough (Sood et al., 2018). This partial normalization could be attributed to impairment of the bronchodilating effect of DIs in COUGH. Overall, the methacholine-induced bronchoconstriction $\left[\triangle \mathrm{FEV}_{1}\right.$ (\%pr)] is consistent with the concept of a continuum across for the four groups, from CA to CVA, to COUGH and CONTROL. Interestingly, the bronchodilating effect of DIs has recently been found to be reduced in children with exercise-induced (indirect) vs. methacholine-induced (direct) bronchoprovocation (Ioan et al., 2017). Ioan et al. (2017) suggest that bronchoconstriction and airway inflammation have "opposite" effects on the impact of DIs on bronchodilation. It would be of interest to tease out the bronchodilating ability of the COUGH group comparing direct vs. indirect bronchoprovocation tests.

COUGH participants developed dyspnea comparable to CA and CVA in response to high-dose methacholine, despite lower levels of bronchoconstriction and gas trapping. The magnitude of the breathlessness scores in our COUGH participants was slightly higher than what has been reported previously in CA (Lougheed et al., 2006), yet their declines in $\mathrm{FEV}_{1}$ and FVC were comparable to those in healthy participants. In the study by Lougheed et al. (2006), the IC for asthma participants decreased by $600 \mathrm{~mL}$ at $\mathrm{PC}_{20}$, whereas in our COUGH participants, IC decreased by $340 \mathrm{~mL}$ at the maximum methacholine dose. COUGH participants also developed cough comparable to CVA, significantly higher compared to both CA and CONTROL groups. Recently, Ohkura et al. (2012) showed that the cough response to bronchoconstriction was heightened in individuals with CVA, in the absence of increased cough reflex sensitivity to capsaicin. Despite being on controller medication, which is known to decrease cough in CVA (Ohkura et al., 2012), cough counts were higher in our CVA and COUGH groups. That participants with COUGH developed cough comparable to CVA and have an increased perception of dyspnea are important novel findings, which further support our hypothesis that COUGH is a clinically distinct phenotype, separate from CVA (based on $\mathrm{PC}_{20}$ ) and from health (based on cough frequency and dyspnea). Our observations also raise the question of whether lung or upper airway afferents contribute to the sensations in the COUGH group (Mazzone and Undem, 2016).

COUGH patients present a unique clinical challenge, both diagnostically and therapeutically. A negative methacholine test is often used to rule out current asthma as the cause of chronic cough (Brown et al., 2007). However, the ongoing respiratory symptoms, particularly chronic cough, are associated with significant morbidity and reduced quality of life (Ford et al., 2006). These patients are often prescribed inhaled rescue bronchodilators and/or asthma controller medications, while they undergo extensive testing to investigate for asthma-like conditions (such as non-asthmatic eosinophilic bronchitis). It is possible that individuals with COUGH lie 
TABLE 3 | Select responses during the modified high-dose methacholine challenge.

\begin{tabular}{|c|c|c|c|c|c|}
\hline & $\begin{array}{c}\text { CA } \\
(n=11)\end{array}$ & $\begin{array}{c}\text { CVA } \\
(n=10)\end{array}$ & $\begin{array}{l}\text { Cough } \\
(n=7)\end{array}$ & $\begin{array}{l}\text { Control } \\
(n=15)\end{array}$ & $P$-value \\
\hline \multicolumn{6}{|l|}{ Sensory responses } \\
\hline Borg overall & $2.7 \pm 1.7^{(n=10)}$ & $2.1 \pm 2.2^{(n=8)}$ & $2.8 \pm 1.8^{(n=6)}$ & $0.5 \pm 0.9$ & 0.004 \\
\hline \multicolumn{6}{|l|}{ Spirometry } \\
\hline$\% \Delta \mathrm{FEV}_{1}$ & $-37.0 \pm 9.5$ & $-34.1 \pm 9.2$ & $-21.6 \pm 15.1$ & 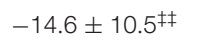 & $<0.001$ \\
\hline$\Delta \mathrm{FVC}(\% \mathrm{pr})$ & $-27.9 \pm 9.6$ & $-21.8 \pm 8.9$ & $-12.2 \pm 14.4$ & $-6.3 \pm 4.3$ & $<0.001$ \\
\hline$\Delta \mathrm{FEV}_{1} / \mathrm{FVC}(\% \mathrm{pr})$ & $-12.3 \pm 6.2^{\ddagger \ddagger}$ & $-15.0 \pm 3.9^{\ddagger \ddagger}$ & $-10.6 \pm 10.3^{\ddagger \ddagger}$ & $-6.4 \pm 3.5$ & 0.005 \\
\hline$\Delta \mathrm{FEF}_{25-75 \%}(\% \mathrm{pr})$ & $-37.5 \pm 17.7^{\text {㧊 }}$ & $-41.6 \pm 23.4 \neq \ddagger$ & $-31.5 \pm 16.4^{\ddagger \ddagger}$ & $-28.2 \pm 15.5^{\ddagger \ddagger}$ & 0.303 \\
\hline \multicolumn{6}{|l|}{ Lung volumes } \\
\hline$\Delta \mathrm{TLC}(\% \mathrm{pr})$ & $0.9 \pm 2.2$ & $-0.5 \pm 0.8$ & $-0.5 \pm 0.6$ & $0.3 \pm 6.7$ & 0.854 \\
\hline$\Delta \mathrm{RV}(\% \mathrm{pr})$ & $42.1 \pm 13.4^{\text {fł }}$ & $21.2 \pm 12.9^{\ddagger \ddagger}$ & $12.0 \pm 18.9$ & $7.8 \pm 16.9$ & $<0.001$ \\
\hline$\Delta \mathrm{R} 5\left(\mathrm{cmH}_{2} \mathrm{O} / \mathrm{L} / \mathrm{s}\right)$ & $2.67 \pm 1.20^{\ddagger \ddagger}$ & $2.33 \pm 1.70^{\ddagger \ddagger}$ & $2.48 \pm 2.03^{\ddagger \ddagger}$ & $2.54 \pm 1.60^{\ddagger \ddagger}$ & 0.971 \\
\hline$\Delta \mathrm{R} 20\left(\mathrm{cmH}_{2} \mathrm{O} / \mathrm{L} / \mathrm{s}\right)$ & $-0.23 \pm 0.68$ & $-0.02 \pm 0.90$ & $0.77 \pm 0.81^{\text {扞 }}$ & $1.01 \pm 0.81^{\text {㧊}}$ & $<0.001$ \\
\hline$\Delta \mathrm{R} 5-\mathrm{R} 20\left(\mathrm{cmH}_{2} \mathrm{O} / \mathrm{L} / \mathrm{s}\right)$ & $2.89 \pm 1.41^{\text {扞 }}$ & $2.34 \pm 1.59$ 㧊 & $1.70 \pm 2.10$ & $1.35 \pm 1.06^{\ddagger \ddagger}$ & $<0.001$ \\
\hline$\Delta \times 5\left(\mathrm{cmH}_{2} \mathrm{O} / \mathrm{L} / \mathrm{s}\right)$ & $-4.30 \pm 2.71^{\text {㧊 }}$ & $-3.52 \pm 2.69^{\ddagger \ddagger}$ & $-1.52 \pm 2.35^{(n=6) \text { 扞 }}$ & $-1.30 \pm 0.88^{\ddagger \ddagger}$ & $<0.001$ \\
\hline$\Delta \mathrm{AX}\left(\mathrm{cmH}_{2} \mathrm{O} / \mathrm{L}\right)$ & $40.52 \pm 26.4^{\text {扞 }}$ & 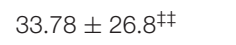 & $16.33 \pm 25.1$ & $13.28 \pm 13.97^{\text {㧊 }}$ & 0.002 \\
\hline$\Delta$ Fres $(\mathrm{Hz})$ & 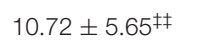 & $11.23 \pm 5.49^{\ddagger \ddagger}$ & $7.33 \pm 4.38^{\text {㧊 }}$ & $10.68 \pm 5.51^{\text {㧊 }}$ & 0.343 \\
\hline
\end{tabular}

All values are mean $\pm S D$. $\Delta=$ change from baseline to MAX. Bolded values indicate significant differences. For definitions of abbreviations, see Table 1. ${ }^{\ddagger \pm} p<0.05$, compared to baseline using paired t-test or Wilcoxon signed-rank test, as appropriate.

TABLE 4 | ANOVA results of responses during the modified high-dose methacholine challenge.

\begin{tabular}{|c|c|c|c|c|c|c|c|}
\hline & CA vs. CVA & CA vs. Cough & CA vs. Control & $\begin{array}{l}\text { CVA vs. } \\
\text { Cough }\end{array}$ & $\begin{array}{l}\text { CVA vs. } \\
\text { Control }\end{array}$ & $\begin{array}{l}\text { Cough vs. } \\
\text { Control }\end{array}$ & $P$-value \\
\hline \multicolumn{8}{|l|}{ Sensory responses } \\
\hline Borg overall & & & 0.010 & & & 0.029 & 0.004 \\
\hline \multicolumn{8}{|l|}{ Spirometry } \\
\hline$\% \Delta \mathrm{FEV}_{1}$ & & 0.033 & $<0.001$ & & 0.001 & & $<0.001$ \\
\hline$\Delta \mathrm{FVC}(\% \mathrm{pr})$ & & 0.005 & $<0.001$ & & 0.001 & & $<0.001$ \\
\hline$\Delta \mathrm{FEV}_{1} / \mathrm{FVC}(\% \mathrm{pr})$ & & & & & 0.005 & & 0.005 \\
\hline$\Delta \mathrm{FEF}_{25-75 \%}(\% \mathrm{pr})$ & & & & & & & 0.303 \\
\hline \multicolumn{8}{|l|}{ Lung volumes } \\
\hline$\Delta T L C(\% p r)$ & & & & & & & 0.854 \\
\hline$\Delta \mathrm{RV}(\% \mathrm{pr})$ & 0.023 & 0.002 & $<0.001$ & & & & $<0.001$ \\
\hline$\Delta \mathrm{R} 5\left(\mathrm{cmH}_{2} \mathrm{O} / \mathrm{L} / \mathrm{s}\right)$ & & & & & & & 0.971 \\
\hline$\Delta \mathrm{R} 20\left(\mathrm{cmH}_{2} \mathrm{O} / \mathrm{L} / \mathrm{s}\right)$ & & 0.034 & 0.002 & & 0.010 & & $<0.001$ \\
\hline$\Delta \mathrm{R} 5-\mathrm{R} 2 \mathrm{O}\left(\mathrm{cmH}_{2} \mathrm{O} / \mathrm{L} / \mathrm{s}\right)$ & & & 0.002 & & & & $<0.001$ \\
\hline$\Delta \times 5\left(\mathrm{cmH}_{2} \mathrm{O} /\llcorner/ \mathrm{s})\right.$ & & 0.008 & 0.001 & 0.033 & 0.003 & & $<0.001$ \\
\hline$\Delta \mathrm{AX}\left(\mathrm{cmH}_{2} \mathrm{O} / \mathrm{L}\right)$ & & 0.022 & 0.006 & 0.011 & 0.002 & & 0.002 \\
\hline$\Delta$ Fres $(\mathrm{Hz})$ & & & & & & & 0.343 \\
\hline
\end{tabular}



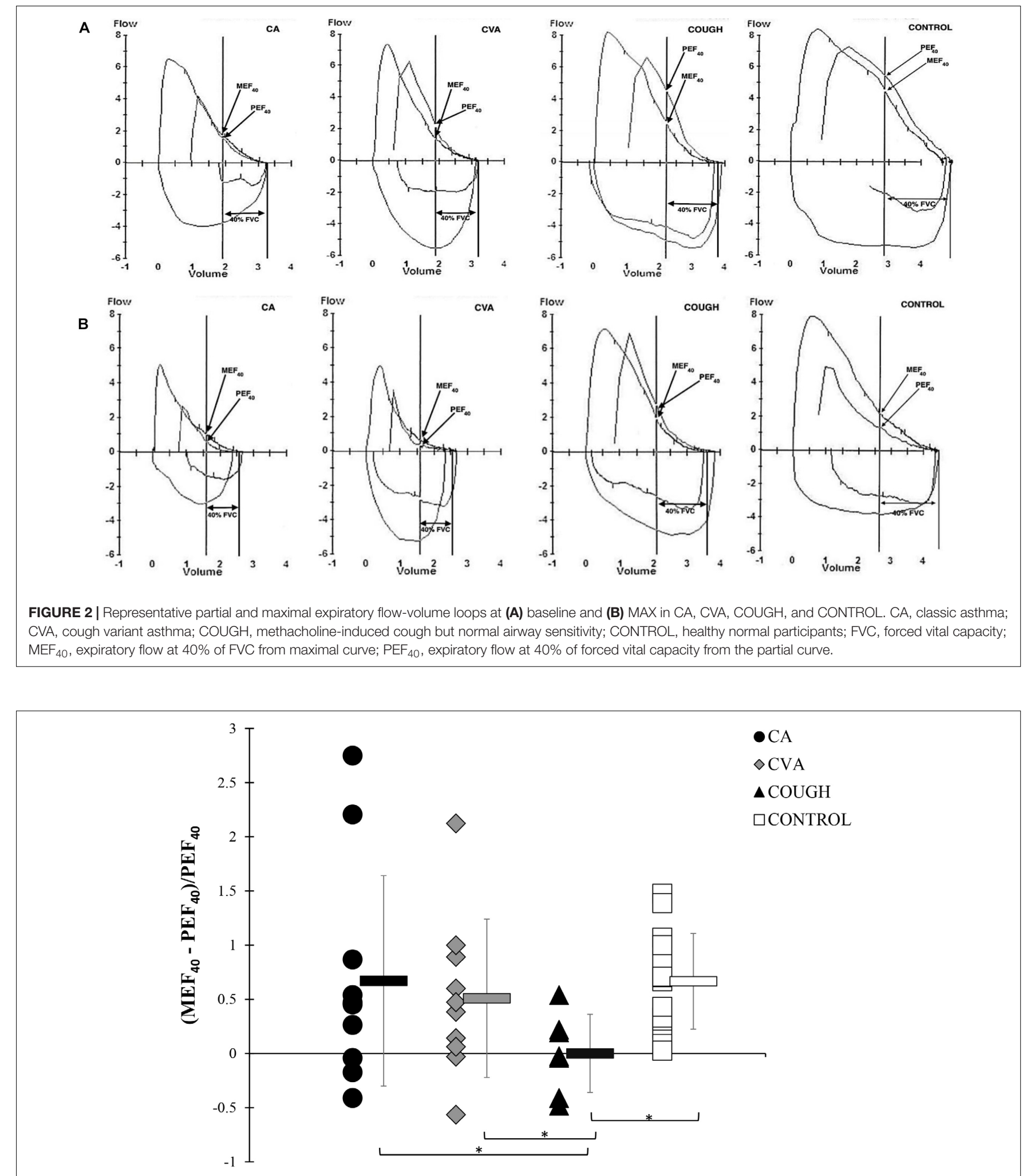

FIGURE 3 | DI indices at MAX during the modified high-dose methacholine challenge in CA, CVA, COUGH, and CONTROL. * denotes $p<0.05$. CA, classic asthma; COUGH, methacholine-induced cough but normal airway sensitivity; CONTROL, healthy normal participants; CVA, cough variant asthma; DI, deep inspiration; $\mathrm{MEF}_{40}$, expiratory flow at $40 \%$ of the forced vital capacity from the full forced vital capacity maneuver; MAX, maximal administered dose of methacholine; $P E F_{40}$, expiratory flow at $40 \%$ of forced vital capacity from the partial curve. 
TABLE 5 | Correlation between impulse oscillometry and DI $(n=42)$.

\begin{tabular}{|c|c|c|c|}
\hline & $\begin{array}{l}\text { Correlation } \\
\text { coefficient }\end{array}$ & $\begin{array}{c}\text { Raw } \\
P \text {-value }\end{array}$ & $\begin{array}{c}\text { False discovery } \\
\text { rate }\end{array}$ \\
\hline \multicolumn{4}{|c|}{ Unadjusted pearson correlation coefficients } \\
\hline $\log (R 5)$ & 0.24 & 0.115 & 0.173 \\
\hline LogR20) & 0.26 & 0.102 & 0.173 \\
\hline $\begin{array}{l}\log (\mathrm{R} 5- \\
\mathrm{R} 20)\end{array}$ & 0.20 & 0.188 & 0.226 \\
\hline $\log (A X)$ & 0.26 & 0.099 & 0.173 \\
\hline$-\log (-X 5)$ & -0.17 & 0.280 & 0.280 \\
\hline Log(Fres) & 0.32 & 0.041 & 0.173 \\
\hline \multicolumn{4}{|c|}{ Partial pearson correlations controlling for age, sex, height, and BM } \\
\hline $\log (R 5)$ & 0.32 & 0.050 & 0.066 \\
\hline $\log (\mathrm{R} 20)$ & 0.20 & 0.239 & 0.239 \\
\hline $\begin{array}{l}\log (\mathrm{R} 5- \\
\mathrm{R} 20)\end{array}$ & 0.33 & 0.044 & 0.066 \\
\hline $\log (A X)$ & 0.34 & 0.041 & 0.066 \\
\hline$-\log (-X 5)$ & -0.32 & 0.055 & 0.066 \\
\hline Log(Fres) & 0.44 & 0.007 & 0.042 \\
\hline \multicolumn{4}{|c|}{ Partial pearson correlations controlling for first five PCs of 22 covariates } \\
\hline $\log (\mathrm{R} 5)$ & 0.41 & 0.015 & 0.023 \\
\hline $\log (\mathrm{R} 20)$ & 0.28 & 0.101 & 0.101 \\
\hline $\begin{array}{l}\log (\mathrm{R} 5- \\
\mathrm{R} 20)\end{array}$ & 0.41 & 0.015 & 0.023 \\
\hline $\log (A X)$ & 0.51 & 0.002 & 0.006 \\
\hline$-\log (-X 5)$ & -0.48 & 0.037 & 0.044 \\
\hline Log(Fres) & 0.59 & 0.0002 & 0.001 \\
\hline
\end{tabular}

PCs, principal components; $R 5$, resistance at $5 \mathrm{~Hz}$ (total respiratory resistance); R5-R20, frequency dependence of Rrs (R5 minus R20, peripheral respiratory resistance); $R 20$, resistance at $20 \mathrm{~Hz}$ (central respiratory resistance); $X 5$, reactance at $5 \mathrm{~Hz}$ (peripheral reactance); $A X$, area under the reactance curve below resonant frequency; Fres, resonant frequency. ${ }^{*} 22$ covariates include age, sex, height, $B M I, 11$ spirometry variables (FEV $, \Delta F E V_{1}, \% p r \Delta F E V_{1}, F V C, \Delta F V C, \% p r \Delta F V C$, $\left.F E V_{1} / F V C, P E F, F E F_{50 \%}, F E F_{25-75 \%}, F E F_{75 \%}\right)$, and seven lung volume measures (TLC, RV, RV/TLC, FRC, ERV, IC, IC/TLC). False discovery rates were calculated within each adjustment group to account for six tests performed.

on a continuum of airway response severity, with the normal healthy response on one end and the impaired response in airway disorders, such as CVA and CA on the other. The underlying pathophysiological mechanisms remain unknown, although the clinical phenotype and presence of some baseline peripheral airway abnormality may reflect the impact of early "subclinical" airway remodeling and could prove useful in early disease detection. Further research is needed to understand whether COUGH represents a distinct disease state or a "prepathological" phenotype at risk of deteriorating over time to develop CVA or severe CA.

\section{Assessing IOS Measures as Predictors of DI Index}

To our knowledge, this is the first study that examines the relationship between IOS parameters and DI Index. Our results demonstrate $\log$ (Fres) and $\log (\mathrm{R} 5-\mathrm{R} 20)$ are the strongest IOS predictors for DI index, with an increase in R5-R20 or decrease in Fres, resulting in a significant decrease in DI Index. Recently, Foy et al. (2019) used CT-guided computational modeling to show that constriction of peripheral airways (diameter $<1.39 \mathrm{~mm}$ ) plays a dominant role in increasing R5-R20 values. We found that participants with COUGH had elevated baseline R5-R20, comparable to CA and CVA, indicating some level of baseline peripheral airway abnormality. This is a novel observation in COUGH, given that this group does not meet the current diagnostic criteria for either CA or CVA.

Preliminary results from the ATLANTIS study have demonstrated peripheral airway resistance (R5-R20) and hyperinflation (RV/TLC) to be strongly positively correlated with the prevalence of small airway disease in asthma (Postma et al., 2019). This finding is replicated in our model with R5-R20 and RV/TLC as significant predictors of a decreased DI Index. We also found Fres to be a strong predictor of an increased DI Index. Fres is thought to mark the transition from small airway obstruction (capacitive dominance at low frequencies) to large airway obstruction (inertial dominance at high frequencies) (Brashier and Salvi, 2015). Individuals with CA and CVA had elevated Fres at baseline, which reflects underlying peripheral airway obstruction present in these groups. Interestingly, at baseline, individuals with COUGH had borderline elevated Fres values, indicating some level of baseline peripheral airway obstruction in this group. Future studies using IOS using direct and indirect airway bronchoprovocation would allow further understanding of the involvement of peripheral airways and the effects of DIs in COUGH.

\section{Limitations}

The small sample size of the COUGH group $(n=7)$ limited our analysis and the interpretation of non-significant differences between the groups. The small sample size also limited our ability to provide reliable individual parameter estimates for the IOS measurements in the multiple regression analysis predicting DI-index. It is possible that further differences exist, and a larger sample would help verify our observations. The age and demographics of the recruited CA, CVA, and COUGH participants are typical of the patient population referred to tertiary cough/asthma clinics. Furthermore, the CONTROL group was recruited to match the other three groups in terms of age and sex, which may limit the generalizability of our findings. For most measurements, we presented the $\%$ predicted values to account for the age- and sex-related differences, but it is possible that further differences exist.

Our CA group consisted of participants with mostly mildto-moderate airway hypersensitivity to methacholine (7/11), whereas all CVA participants had borderline-to-mild airway hypersensitivity. It is possible that the inclusion of participants with more severe asthma may yield different results. There was also some overlap in asthma severity (in terms of $\mathrm{PC}_{20}$ ) between the CA and CVA groups. Even within the COUGH and CONTROL groups, there was a variable response to methacholine (Sood et al., 2017), which could affect the interpretation of our results. Interestingly, cough with normal airway sensitivity has also been described during mannitol challenge (Koskela et al., 2004, 2018; Turcotte and Lougheed, 2011) and hypertonic saline and hypertonic histamine challenges (Koskela et al., 2005). Future studies could use another stimulus 
(e.g., mannitol and cold air) to elucidate further pathophysiologic differences between the four groups.

Some participants in the CA, CVA, and COUGH groups were using inhaled corticosteroids as maintenance therapy and did not withhold these prior to methacholine challenge. Inhaled corticosteroid use, even at low doses, is known to suppress airway inflammation in asthma and, therefore, may be associated with a decreased sensitivity to methacholine (Fujimura et al., 2005). We used a methacholine threshold of $16 \mathrm{mg} / \mathrm{mL}$ to minimize any resulting diagnostic misclassification based on previous work by Luks et al. (2010). However, approximately $73 \%$ of participants with CA, 40\% with CVA, and 43\% with COUGH were taking an inhaled corticosteroid prior to study enrollment, which could have attenuated their responses and/or sensitivity to methacholine. Medication use may also have impacted our participants' response to DIs as demonstrated by Bel et al. (1990), where prior use of anti-inflammatory (leukotriene inhibitor) therapy enhanced of DI-induced bronchodilation during methacholine challenge.

\section{CONCLUSION}

Our main finding is that the bronchodilating effect of DIs is impaired in COUGH, compared to healthy normals and asthma. Our IOS data have provided novel insights into the involvement of peripheral airways in the bronchodilating effects of DIs. Decreased Fres and increased R5-R20 are predictive of a decreased ability to bronchodilate after a DI. In COUGH, dyspnea intensity and cough frequency in response to highdose methacholine are comparable to CA and CVA, respectively, despite mechanical responses comparable to healthy normals. COUGH is a distinct and clinically relevant airway disorder related to impaired peripheral airway function.

\section{DATA AVAILABILITY STATEMENT}

The data that support the findings of this study are available on request from the corresponding author NS,0ns10@queensu.ca. The data for the control participants are available on request at doi: 10.5683/SP2/HECUFP.

\section{REFERENCES}

Bel, E. H., Timmers, M. C., Dijkman, J. H., Stahl, E. G., and Sterk, P. J. (1990). The effect of an inhaled leukotriene antagonist, L-648,051, on early and late asthmatic reactions and subsequent increase in airway responsiveness in man. J. Allergy Clin. Immunol. 85, 1067-1075. doi: 10.1016/0091-6749(90)9 0052-6

Birring, S., Prudon, B., Carr, A., Singh, S., Morgan, M., and Pavord, I. (2003). Development of a symptom specific health status measure for patients with chronic cough: leicester cough questionnaire (LCQ). Thorax 58, 339-343. doi: 10.1136/thorax.58.4.339

Borg, G. A. (1982). Psychophysical bases of perceived exertion. Med. Sci. Sports Exerc. 14, 377-381.

Borrill, Z. L., Houghton, C. M., Woodcock, A. A., Vestbo, J., and Singh, D. (2005). Measuring bronchodilation in COPD clinical trials. $\mathrm{Br}$.

\section{ETHICS STATEMENT}

The studies involving human participants were reviewed and approved by the Queen's University Health Sciences and Affiliated Teaching Hospitals Research Ethics Board (HSREB). The patients/participants provided their written informed consent to participate in this study.

\section{AUTHOR CONTRIBUTIONS}

NS performed experiments, analyzed the data, interpreted results of experiments, prepared figures and tables, drafted the manuscript, edited and revised the manuscript, and approved the final version of the manuscript. NW performed experiments, analyzed the data, and approved the final version of the manuscript. AD analyzed the data, interpreted results of experiments, prepared figures and tables, and approved the final version of the manuscript. TW and TF performed experiments and approved the final version of the manuscript. JF edited and revised the manuscript, and approved the final version of the manuscript. ML conceived and designed research, interpreted results of experiments, drafted, edited, and revised the manuscript, and approved the final version of the manuscript. All authors contributed to the article and approved the submitted version.

\section{FUNDING}

This study was funded by the Queen's University William M. Spear Endowment/Start Memorial Fund and the Ontario Thoracic Society.

\section{SUPPLEMENTARY MATERIAL}

The Supplementary Material for this article can be found online at: https://www.frontiersin.org/articles/10.3389/fphys. 2020.554679/full\#supplementary-material

J. Clin. Pharmacol. 59, 379-384. doi: 10.1111/j.1365-2125.2004.02 261.x

Brashier, B., and Salvi, S. (2015). Measuring lung function using sound waves: role of the forced oscillation technique and impulse oscillometry system. Breathe 11, 57-65. doi: 10.1183/20734735.02 0514

Briscoe, W. A., and Dubois, A. B. (1958). The relationship between airway resistance, airway conductance and lung volume in subjects of different age and body size12. J. Clin. Invest. 37, 12791285.

Brown, N. J., Salome, C. M., Berend, N., Thorpe, C. W., and King, G. G. (2007). Airway distensibility in adults with asthma and healthy adults, measured by forced oscillation technique. Am. J. Respir. Crit. Care Med. 176, 129-137. doi: 10.1164/rccm.200609-13 17OC 
Chapman, D. G., Berend, N., King, G. G., McParland, B. E., and Salome, C. M. (2009). Deep inspirations protect against airway closure in nonasthmatic subjects. J. Appl. Physiol. 107, 564-569. doi: 10.1152/japplphysiol.00202. 2009

Chung, K. F., Bolser, D., Davenport, P., Fontana, G., Morice, A., and Widdicombe, J. (2009). Semantics and types of cough. Pulm. Pharmacol. Ther. 22, 139-142. doi: 10.1016/j.pupt.2008.12.008

Corrao, W. M., Braman, S. S., and Irwin, R. S. (1979). Chronic cough as the sole presenting manifestation of bronchial asthma. N. Engl. J. Med. 300, 633-637. doi: 10.1056/NEJM1979032230 01201

Crapo, R. O., Casaburi, R., Coates, A. L., Enright, P. L., Hankinson, J. L., Irvin, C. G., et al. (2000). Guidelines for methacholine and exercise challenge testing-1999. This official statement of the American Thoracic Society was adopted by the ATS Board of Directors, July 1999. Am. J. Respir. Crit. Care Med. 161, 309-329. doi: 10.1164/ajrccm.161.1.ats 11-99

Dweik, R. A., Boggs, P. B., Erzurum, S. C., Irvin, C. G., Leigh, M. W., Lundberg, J. O., et al. (2011). An official ATS clinical practice guideline: interpretation of exhaled nitric oxide levels (FENO) for clinical applications. Am. J. Respir. Crit. Care Med. 184, 602-615. doi: 10.1164/rccm.9120$11 \mathrm{ST}$

Ford, A. C., Forman, D., Moayyedi, P., and Morice, A. H. (2006). Cough in the community: a cross sectional survey and the relationship to gastrointestinal symptoms. Thorax 61, 975-979. doi: 10.1136/thx.2006.06 0087

Foy, B. H., Soares, M., Bordas, R., Richardson, M., Bell, A., Singapuri, A., et al. (2019). Lung Computational Models and the Role of the Small Airways in Asthma. Am. J. Respir. Crit. Care Med. 200, 982-991. doi: 10.1164/rccm.201812$2322 \mathrm{OC}$

Fujimura, M., Hara, J., and Myou, S. (2005). Change in bronchial responsiveness and cough reflex sensitivity in patients with cough variant asthma: effect of inhaled corticosteroids. Cough Lond. Engl. 1:5. doi: 10.1186/17459974-1-5

Fujimura, M., Nomura, M., Sakamoto, S., Kamio, Y., Shibata, K., Ogawa, H., et al. (1990). [Effect of deep inspiration on maximum expiratory flow (Vmax) depends on basal bronchomotor tone in young healthy females]. Nihon Kyobu Shikkan Gakkai Zasshi 28, 105-112.

Glauser, F. L. (1972). Variant asthma. Ann. Allergy 30, 457-459.

Goldman, H. I., and Becklake, M. R. (1959). Respiratory function tests; normal values at median altitudes and the prediction of normal results. Am. Rev. Tuberc. 79, 457-467. doi: 10.1164/artpd.1959.79. 4.457

Ioan, I., Tatopoulos, A., Metche, S., Coutier, L., Houriez, E., Kiefer, S., et al. (2017). More relaxation by deep breath on methacholine- than on exercise-induced bronchoconstriction during the routine testing of asthmatic children. Front. Physiol. 8:768. doi: 10.3389/fphys.2017. 00768

Irwin, R. S., Baumann, M. H., Bolser, D. C., Boulet, L.-P., Braman, S. S., Brightling, C. E., et al. (2006). Diagnosis and management of cough executive summary: ACCP evidence-based clinical practice guidelines. Chest 129, 1S-23S. doi: 10. 1378/chest.129.1_suppl.1S

Juniper, E. F., Guyatt, G. H., Cox, F. M., Ferrie, P. J., and King, D. R. (1999). Development and validation of the mini asthma quality of life questionnaire. Eur. Respir. J. 14, 32-38. doi: 10.1034/j.1399-3003.1999. 14a08.x

Kaminsky, D. A. (2011). Peripheral lung mechanics in asthma: exploring the outer limits. Pulm. Pharmacol. Ther. 24, 199-202. doi: 10.1016/j.pupt.2010. 12.001

Koskela, H. O., Hyvärinen, L., Brannan, J. D., Chan, H.-K., and Anderson, S. D. (2004). Coughing during mannitol challenge is associated with asthma. Chest 125, 1985-1992. doi: 10.1378/chest.125.6.1985

Koskela, H. O., Kontra, K. M., Purokivi, M. K., and Randell, J. T. (2005). Interpretation of cough provoked by airway challenges. Chest 128, 3329-3335. doi: 10.1378/chest.128.5.3329

Koskela, H. O., Lake, C., Wong, K., and Brannan, J. D. (2018). Cough sensitivity to mannitol inhalation challenge identifies subjects with chronic cough. Eur. Respir. J. 51, 1800294. doi: 10.1183/13993003.002942018

LaPrad, A. S., and Lutchen, K. R. (2008). Respiratory impedance measurements for assessment of lung mechanics: focus on asthma. Respir. Physiol. Neurobiol. 163, 64-73. doi: 10.1016/j.resp.2008.04.015

Lougheed, M. D., Fisher, T., and O’Donnell, D. E. (2006). Dynamic hyperinflation during bronchoconstriction in asthma: implications for symptom perception. Chest 130, 1072-1081. doi: 10.1378/chest.130.4. 1072

Lougheed, M. D., Lam, M., Forkert, L., Webb, K. A., and O’Donnell, D. E. (1993). Breathlessness during acute bronchoconstriction in asthma. Pathophysiologic mechanisms. Am. Rev. Respir. Dis. 148, 1452-1459. doi: 10.1164/ajrccm/148.6 Pt_1.1452

Lougheed, M. D., Lemiere, C., Ducharme, F. M., Licskai, C., Dell, S. D., Rowe, B. H., et al. (2012). Canadian Thoracic Society 2012 guideline update: diagnosis and management of asthma in preschoolers, children and adults. Can. Respir. J. 19, 127-164. doi: 10.1155/2012/63 5624

Luks, V. P., Vandemheen, K. L., and Aaron, S. D. (2010). Confirmation of asthma in an era of overdiagnosis. Eur. Respir. J. 36, 255-260. doi: 10.1183/09031936. 00165109

Marotta, A., Klinnert, M. D., Price, M. R., Larsen, G. L., and Liu, A. H. (2003). Impulse oscillometry provides an effective measure of lung dysfunction in 4-year-old children at risk for persistent asthma. J. Allergy Clin. Immunol. 112, 317-322. doi: 10.1067/mai.2003. 1627

Mazzone, S. B., and Undem, B. J. (2016). Vagal afferent innervation of the airways in health and disease. Physiol. Rev. 96, 975-1024. doi: 10.1152/physrev.00039.2015

Miller, M. R., Hankinson, J., Brusasco, V., Burgos, F., Casaburi, R., Coates, A., et al. (2005). Standardisation of spirometry. Eur. Respir. J. 26, 319-338. doi: 10.1183/09031936.05.00034805

Morice, A. H. (2008). Rebuttal: cough is an expiratory sound. Lung 186(Suppl. 1), S7-S9. doi: 10.1007/s00408-007-9039-5

Morris, J. F., Koski, A., and Johnson, L. C. (1971). Spirometric standards for healthy nonsmoking adults. Am. Rev. Respir. Dis. 103, 57-67. doi: 10.1164/arrd.1971. 103.1.57

Navajas, D., and Farré, R. (2001). Forced oscillation assessment of respiratory mechanics in ventilated patients. Crit. Care Lond. Engl. 5, 3-9. doi: 10.1186/ cc972

Ohkura, N., Fujimura, M., Nakade, Y., Okazaki, A., and Katayama, N. (2012). Heightened cough response to bronchoconstriction in cough variant asthma. Respirol. Carlton Vic 17, 964-968. doi: 10.1111/j.1440-1843.2012.02 208.x

Ohkura, N., Fujimura, M., Tokuda, A., Hara, J., Hori, A., Nishitsuji, M., et al. (2009). Bronchodilator effect of deep inspiration and bronchoconstrictiontriggered cough. Cough Lond. Engl. 5:9. doi: 10.1186/1745-99 74-5-9

Ohkura, N., Fujimura, M., Tokuda, A., Nakade, Y., Nishitsuji, M., Abo, M., et al. (2010). Bronchoconstriction-triggered cough is impaired in typical asthmatics. J. Asthma Off. J. Assoc. Care Asthma 47, 51-54. doi: 10.3109/ 02770900903362650

Oostveen, E., MacLeod, D., Lorino, H., Farré, R., Hantos, Z., Desager, K., et al. (2003). The forced oscillation technique in clinical practice: methodology, recommendations and future developments. Eur. Respir. J. 22, 1026-1041. doi: 10.1183/09031936.03.00089403

Postma, D. S., Brightling, C., Baldi, S., Van den Berge, M., Fabbri, L. M., Gagnatelli, A., et al. (2019). Exploring the relevance and extent of small airways dysfunction in asthma (ATLANTIS): baseline data from a prospective cohort study. Lancet Respir. Med. 7, 402-416. doi: 10.1016/S2213-2600(19)30 049-9

Rodenstein, D. O., and Stânescu, D. C. (1983). Absence of nasal air flow during pursed lips breathing. The soft palate mechanisms. Am. Rev. Respir. Dis. 128, 716-718. doi: 10.1164/arrd.1983.128. 4.716

Sangha, O., Stucki, G., Liang, M. H., Fossel, A. H., and Katz, J. N. (2003). The selfadministered comorbidity questionnaire: a new method to assess comorbidity for clinical and health services research. Arthritis Care Res. 49, 156-163. doi: 10.1002/art.10993 
Sood, N., Fisher, T., Wall, T., Fisher, J. T., and Lougheed, M. D. (2017). "Sensorymechanical responses to high-dose methacholine bronchoprovocation in healthy normal subjects," in A101. ADVANCES IN COUGH, DYSPNEA, AND INTERVENTIONAL PULMONARY American Thoracic Society International Conference Abstracts, (New York, NY: American Thoracic Society), A2670A2670.

Sood, N., Turcotte, S. E., Wasilewski, N. V., Fisher, T., Wall, T., Fisher, J. T., et al. (2018). Small-airway obstruction, dynamic hyperinflation, and gas trapping despite normal airway sensitivity to methacholine in adults with chronic cough. J. Appl. Physiol. 126, 294-304. doi: 10.1152/japplphysiol.00635. 2018

Sterk, P. J., Daniel, E. E., Zamel, N., and Hargreave, F. E. (1985). Limited bronchoconstriction to methacholine using partial flow-volume curves in nonasthmatic subjects. Am. Rev. Respir. Dis. 132, 272-277. doi: 10.1164/arrd. 1985.132.2.272

Turcotte, S. E., and Lougheed, M. D. (2011). Cough in asthma. Curr. Opin. Pharmacol. 11, 231-237. doi: 10.1016/j.coph.2011.04. 008

Wasilewski, N. V., Fisher, T., Turcotte, S. E., Fisher, J. T., and Lougheed, M. D. (2015). Bronchodilating effect of deep inspirations in asthma and chronic cough. J. Appl. Physiol. 120, 1018-1028. doi: 10.1152/japplphysiol.00737. 2015

Wasilewski, N. V., Fisher, T., Turcotte, S. E., Fisher, J. T., and Lougheed, M. D. (2018). Bronchoprotective effect of deep inspirations in cough variant asthma: a distinguishing feature in the spectrum of airway disease? Respir. Physiol. Neurobiol. 257, 55-64. doi: 10.1016/j.resp.2017.09.004

Conflict of Interest: ML has received grants outside the submitted work paid directly to Queen's University from the Ontario Lung Association/Ontario Thoracic Society, the Government of Ontario's Innovation Fund, AllerGen NCE, Queen's University, AstraZeneca, GlaxoSmithKline, Hoffman-La Roche, Janssen, and Novartis, honoraria from the Ontario Lung Association for preparation and review of educational materials, an honorarium from the Canadian Thoracic Society for co-development and co-presentation of the Severe Asthma PREP course, and honoraria from AstraZeneca for participation in the Precision Program Advisory Board.

The remaining authors declare that the research was conducted in the absence of any commercial or financial relationships that could be construed as a potential conflict of interest.

Copyright (c) 2020 Sood, Wasilewski, Day, Wall, Fisher, Fisher and Lougheed. This is an open-access article distributed under the terms of the Creative Commons Attribution License (CC BY). The use, distribution or reproduction in other forums is permitted, provided the original author(s) and the copyright owner(s) are credited and that the original publication in this journal is cited, in accordance with accepted academic practice. No use, distribution or reproduction is permitted which does not comply with these terms. 